a 10-year descriptive cohort in intensive care unit. Ann Intensive Care. 2017;7(1):45.

3. Güzel A, Duran L, Paksu S, Akdemir HU, Paksu MŞ, Kat1 C, et al. Drowning and near-drowning: experience of a university hospital in the Black Sea region. Turk $J$ Pediatr. 2013;55(6):620-7.

4. Tumram NK, Dhawne SG, Ambade VN, Dixit PG. Fatal tusk injuries from a wild boar attack. Med Leg J. 2015; 83(1):54-6.

5. Manipady S, Menezes RG, Bastia BK. Death by attack from a wild boar. J Clin Forensic Med. 2006;13(2): 89-91.

6. Shetty M, Menezes RG, Kanchan T, Shetty BS, Chauhan A. Fatal craniocerebral injury from wild boar attack. Wilderness Environ Med. 2008;19(3):222-3.

7. Chattopadhyay S, Shee B, Sukul B. Fatal crocodile attack. J Forensic Leg Med. 2013;20(8):1139-41.

8. Byard RW, James RA, Heath KJ. Recovery of human remains after shark attack. Am J Forensic Med Pathol. 2006;27(3):256-9.

9. Wolf BC, Harding BE. Fatalities due to indigenous and exotic species in Florida. J Forensic Sci. 2014;59(1): 155-60.

10. Giesbrecht GG. Cold stress, near drowning and accidental hypothermia: a review. Aviat Space Environ Med. 2000; 71(7):733-52

11. Brooks CJ, Howard KA, Neifer SK. How much did cold shock and swimming failure contribute to drowning deaths in the fishing industry in British Columbia 1976-2002. Occup Med (Lond). 2005;55(6):459-62.

\section{Uncommon Skin Response to the Stings of Tropical Fire Ant Solenopsis geminata}

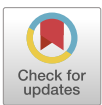

To the Editor:

Ants are insects of the order Hymenoptera (family: Formicidae), and approximately 16,000 ant species are recorded worldwide. ${ }^{1}$ Human fatalities from ant stings are rare, although life-threatening anaphylaxis is not uncommon. ${ }^{2}$ Infants, children, and frail elderly people are the most vulnerable groups for ant stings and related fatalities. ${ }^{2}$

Fire ants of the genus Solenopsis are mostly found in the tropical and temperate parts of the world, including central Asia, Asia Pacific, mid-Europe, Africa, the Pacific islands, and Australia. ${ }^{3}$ The tropical fire ant, Solenopsis geminata, is the most common fire ant found in the urban environment, agricultural lands, houses, and animal sheds in Sri Lanka. ${ }^{4}$ Anaphylaxis and related fatalities following the stings of the red fire ant,
Solenopsis invicta, and the black fire ant, Solenopsis richteri, are commonly reported in other countries. ${ }^{5}$ Although the published literature is scarce, the tropical fire ant $S$ geminata is capable of causing anaphylaxis and cutaneous reactions. ${ }^{6,7}$ The occurrence of sterile pustules at the site of $S$ invicta sting is commonly reported, ${ }^{6-8}$ but reports on the appearance of similar lesions after the $S$ geminata stings are rare in the literature. ${ }^{8}$

\section{Case presentation}

A 13-m-old girl presented with a pustular rash in the lower back and lower limbs to the primary medical care unit (PMCU) in Kendewa, a very remote rural village, in the dry zone of Sri Lanka. The child was apparently healthy when her father placed her on a heap of sand located outside their house the previous morning and the child suddenly started to cry. On examination, the child's parents noticed multiple, small, dull, brownish-yellow ants on her lower back (just above the waistline) and both lower limbs. They removed all ants and washed the stung area with water immediately. The mother noticed redness and mild swelling over the bitten areas of the lower back and both lower limbs of the child. She applied coconut oil as a first aid measure. The child was agitated and irritable throughout this period and attempted to scratch the affected area. The mother applied baby cream and a traditional herbal oil made from Madhuca longifolia (honey tree) that gradually alleviated the the acute irritability. The parents noted multiple yellowish-white pustules throughout the affected areas the following morning and quickly sought medical attention.

On admission to the PMCU, the child was irritable but afebrile. There were multiple yellowish-white pustules of 1 to $2 \mathrm{~mm}$ in size over the lower back, back of the left leg, upper back of the right thigh, and on the anterior lower abdomen above the waistline (Figure 1). There were a few ruptured pustules with clear serum fluid on the lower back without swelling or redness in the area. The affected area was not warm to touch. The child did not have any history of allergies.

The ruptured pustules were cleaned with povidoneiodine, and 2\% mupirocin cream was applied. The child was treated with cloxacillin syrup $125 \mathrm{mg}$ orally every $6 \mathrm{~h}$ for $5 \mathrm{~d}$, chlorpheniramine syrup $1 \mathrm{mg}$ orally twice daily for $3 \mathrm{~d}$, and paracetamol syrup $15 \mathrm{mg} \cdot \mathrm{kg}^{-1}$ orally as needed. The child did not receive any inpatient care and had follow-up care at the PMCU. It took $7 \mathrm{~d}$ for the 


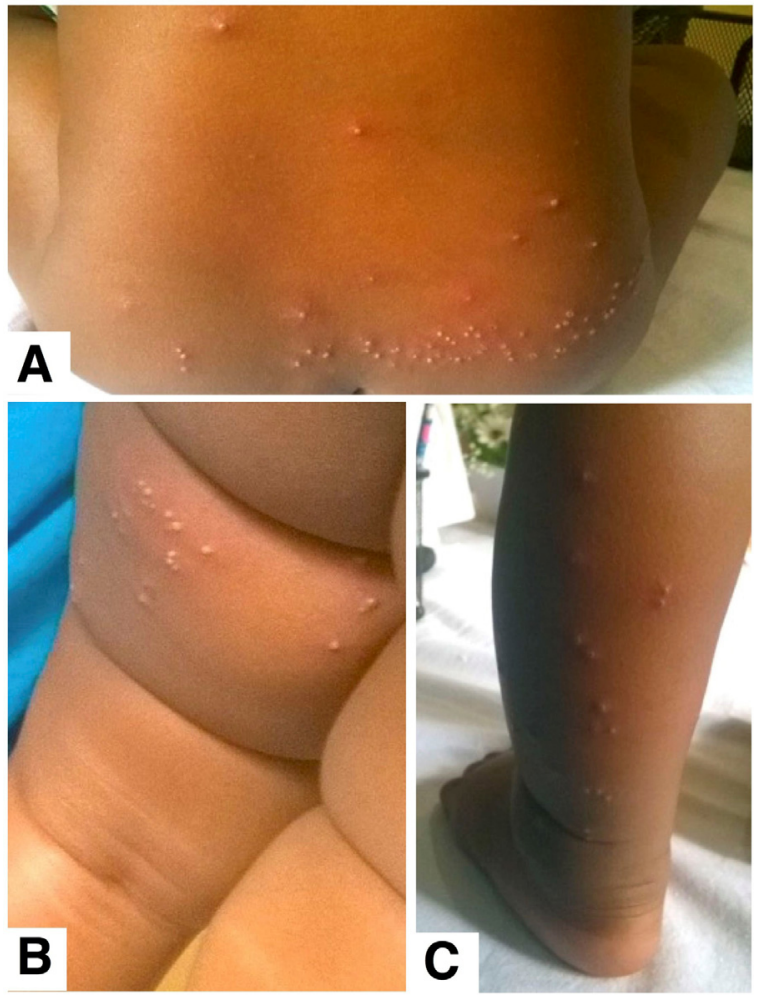

Figure 1. Pustules after Solenopsis geminata stings. A, Above the waistline; B, Below the buttocks; C, Posterior aspect of left leg. pustules to disappear and 2 more weeks for the complete resolution of the scars.

The patient was managed by the second author (GKR), who was the medical officer in charge at the PMCU Kendewa at the time patient presentation and management. We visited the child's home the day after she presented for treatment and collected ant specimens. The ant specimens were examined by an expert in ant identification (RKSD) and identified as the workers of the tropical fire ant $S$ geminata.

\section{Discussion}

Morphologically, the workers of the tropical fire ant $S$ geminata are 3 to $5 \mathrm{~mm}$ in length and are orange to reddish-yellow with a posterior reddish-brown gaster (Figure 2). The worker has a square-shaped head with 10 segmented antennae. The eyes are relatively small with 4 to 6 ommatidia in the longest rows. The mandible has 3 large teeth and a minute fourth tooth. The body is smooth and shiny with sparse body hairs. ${ }^{4,9}$ The apex of the gaster bears a well-developed long stinger. The ants dwell in nests formed in the ground and forage throughout the area. The stinger is used for self-defense. ${ }^{4} \mathrm{~S} \mathrm{gem-}$ inata workers do not bite, but they use the stinger at the tip of the gaster to sting. The venom is released via the sting and injected or sprayed according to the situation. $^{10,11}$
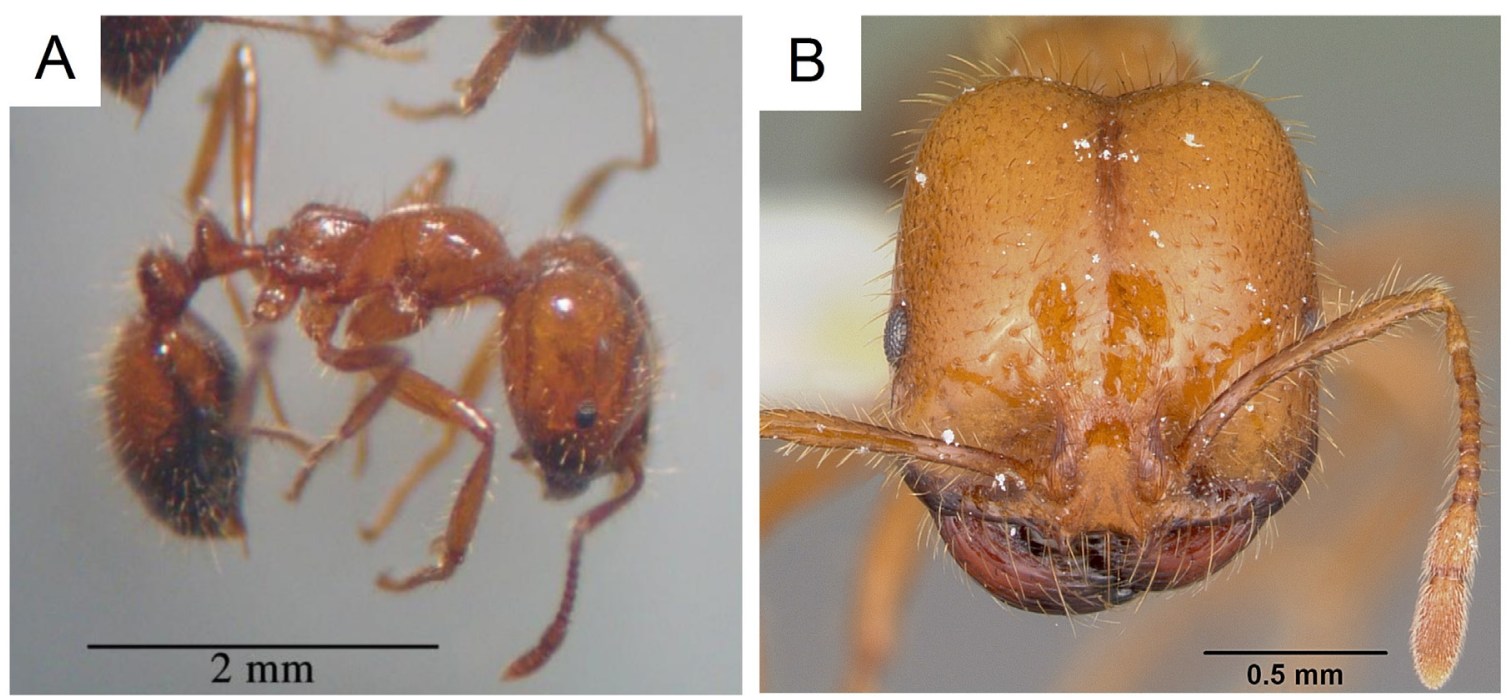

Figure 2. A, Solenopsis geminata workers (photographs by RKS Dias); B, Head of a Solenopsis geminata (photographs by April Nobile. Used with permission from www.antweb.org). 
Fire ants sting by grasping the skin with the mandibles and inserting the stinger into the skin while slowly injecting the venom. ${ }^{9}$ Fire ants can sting repeatedly while maintaining a grip with their mandibles. ${ }^{9}$ The workers as a group, if disturbed, will sting together. They will also use their mandibles to attack (bite) other ant species. ${ }^{10}$ The workers are omnivores and may sting their prey before feeding, not as a defensive action but to paralyze the prey. ${ }^{10,11}$

It is well known that the fire ant $S$ invicta stings are capable of causing sterile pustules, although these are infrequently seen following $S$ xyloni, $S$ Aurea, or $S$ germinata stings. ${ }^{5}$ The fluid appearing in the pustules is initially clear and is then predominated by polymorphs and lymphocyte followed by plasma cells. ${ }^{5}$ No effective treatment for these pustules has been described, however, and they can be secondarily infected after a breach. ${ }^{5}$

Victims of multiple stings, especially in rural areas, should seek treatment promptly for several reasons. In this reported case, notwithstanding the delayed presentation, prompt management at the remote rural clinic may have prevented secondary infection. Admittedly, there is no evidence that prophylactic antibiotics should routinely be recommended for ant bites or stings; however, prophylactic antibiotics were given to this child in consideration of the remote accessibility to a health care center for further management and also due to the likely further application of topical home remedies. Initially, the parents applied home remedies to alleviate stingrelated symptoms, and anti-inflammatory, wound healing, and antimicrobial activity of $M$ longifolia in animal models have been reported. ${ }^{12}$ However, unsterile preparation and application in a rural setting can contribute to secondary infections of excoriated or open lesions. Furthermore, application of alternative medicine has been associated with skin reaction that may complicate the diagnosis and management. ${ }^{13}$ Another reason for prompt evaluation is that any patient with a history of sensitization to some species of Solenopsis stings may develop severe reactions after prospective stings. ${ }^{2}$ Travelers who visit fire ant-endemic areas, especially those who are vespid sensitive, also should be aware of the potential complications, as they are at increased risk of allergic reactions from fire ant stings. ${ }^{8}$

In this case, the scars persisted for a period of 3 weeks. Several villagers who had similar stings and symptoms in the past were interviewed and stated that their scars had persisted for a long period, some lifelong. Similarly, long-lasting scars have been reported following $S$ invitica and $S$ richteri stings. ${ }^{14}$

Acknowledgments: We acknowledge the help extended by Dr. Devarajan Rathish during specimen collection. We thank the anonymous reviewer for the constructive comments, which helped us to improve the manuscript.

Buddhika T.B. Wijerathne, MBBS, PG Dip. Public Health, MPH, MRSPH

Department of Community Medicine, Faculty of Medicine and Allied Sciences, Rajarata University of Sri Lanka, Saliyapura, Sri Lanka

Geetha K. Rathnayake, MBBS Bankstown-Lidcombe Hospital, Sydney, Australia

R.K. Sriyani Dias, BSc, MSc, PhD Department of Zoology and Environmental Management, Faculty of Science, University of Kelaniya, Kelaniya, Sri Lanka

Nuwan D. Wickramasinghe, MBBS, Dip, MSc, MSc, MD, FRSPH

Department of Community Medicine, Faculty of Medicine and Allied Sciences, Rajarata University of Sri Lanka, Saliyapura, Sri Lanka

Sujeewa P.B. Thalgaspitiya, MBBS, MS Department of Surgery, Faculty of Medicine and Allied Sciences, Rajarata University of Sri Lanka, Saliyapura, Sri Lanka

Anuruddha H. Karunaratne, MBBS, Msc Department of Community Medicine, Faculty of Medicine and Allied Sciences, Rajarata University of Sri Lanka, Saliyapura, Sri Lanka

Suneth B. Agampodi, MBBS, MSc, MD, MPH. FRSPH Department of Community Medicine, Faculty of Medicine and Allied Sciences, Rajarata University of Sri Lanka, Saliyapura, Sri Lanka

\section{References}

1. AntWeb. Bolton World Catalog Ants; 2017. Available at: https://www.antweb.org/world.jsp. Accessed February 3, 2017.

2. Desforges JF, DeShazo RD, Butcher BT, Banks WA. Reactions to the stings of the imported fire ant. $N$ Engl J Med. 1990;323(7):462-6.

3. Ettershank G. A generic revision of the world Myrmicinae related to Solenopsis and Pheidologeton (Hymenoptera: Formicidae). Aust J Zool. 1966;14(1):73.

4. Dias SRK. Ants of Sri Lanka. Battaramulla: Biodiversity Secretariat on Ministry of Environmental and Renewable Energy of Sri Lanka; 2014. 
5. Hoffman DR. Fire ant venom allergy. Allergy. 1995;50 (7):535-44.

6. Havaldar PV, Patil SS, Phadnis C. Anaphylaxis due to red fire ant bite. Indian Pediatr. 2012;49(3):237-8.

7. Knight D, Bangs MJ. Cutaneous allergic vasculitis due to Solenopsis geminata (Hymenoptera: Formicidae) envenomation in Indonesia. Southeast Asian J Trop Med Public Health. 2007;38(5):808-13.

8. Hoffman DR. Reactions to less common species of fire ants. J Allergy Clin Immunol. 1997;100(5):679-83.

9. Global Invasive Species Database [online database]. Species profile: Solenopsis geminata. Available at: http://www.iucn gisd.org/gisd/search.php. Accessed January 3, 2018.
10. Abhinandini DI, Venkatesha MG. Antagonistic interactions among common tropical household ant species (Hymenoptera: Formicidae). J Entomol Zool Stud. 2015;3(1):27-32.

11. Trager JC. A revison of the fire ants, Solenopsis geminata group (Hymenoptera: Formicidae: Myrmicinae). J New York Entomol Soc. 1991;99(2):141-98.

12. Akshatha KN, Mahadeva Murthy S, Lakshmidevi AN. Ethnomedical uses of madhuca longifolia - a review. Int J Life Sci Pharma Res. 2013;3(1):44-53.

13. Lilly E, Kundu RV. Dermatoses secondary to Asian cultural practices. Int J Dermatol. 2012;51(4):372-9.

14. deShazo RD, Soto-Aguilar M. Reactions to imported fire ant stings. Allergy Asthma Proc. 1993;14(1):13-6. 